\title{
Adherence to Scheduled Sessions in a Randomized Field Trial of Case Management: The Criminal Justice-Drug Abuse Treatment Studies Transitional Case Management Study
}

\author{
Michael Prendergast • Lisa Greenwell • \\ Jerome Cartier • JoAnn Sacks • Linda Frisman • \\ Eleni Rodis • Jennifer R. Havens
}

Published online: 4 July 2009

(C) The Author(s) 2009. This article is published with open access at Springerlink.com

\begin{abstract}
The Transitional Case Management (TCM) study, one of the projects of the Criminal Justice Drug Abuse Treatment Studies (CJ-DATS) cooperative, was a multi-site randomized test of whether a strengths-based case management intervention provided during an inmate's transition from incarceration to the community increases participation in community substance abuse treatment, enhances access to needed social services, and improves drug use and crime outcomes. As in many intervention studies, TCM experienced a relatively large percentage of treatmentgroup participants who attended few or no scheduled sessions. The paper discusses issues with regard to participation in community case management sessions, examines patterns of session attendance among TCM participants, and analyzes client and case manager characteristics that are associated with number of sessions attended and with patterns of attendance. The average number of sessions (out of 12) attended was 5.7. Few client or case manager characteristics were found to be
\end{abstract}

\footnotetext{
M. Prendergast $(\bowtie) \cdot$ L. Greenwell $\cdot$ J. Cartier Integrated Substance Abuse Programs, Semel Institute for Neuroscience and Human Behavior, University of California Los Angeles, 1640 S. Sepulveda Blvd., Suite 200,

Los Angeles, CA 20025, USA

e-mail: mlp@ucla.edu

J. Sacks

Center for the Integration of Research \& Practice, National Development \& Research Institutes, Inc., New York, NY, USA

L. Frisman $\cdot$ E. Rodis

Research Division, Connecticut Department of Mental Health \& Addiction Services, Hartford, CT, USA

J. R. Havens

Center on Drug and Alcohol Research, University of Kentucky, Lexington, KY, USA
} 
significantly related to session attendance. Clinical and research implications of the findings and of adherence in case management generally are discussed.

Keywords Case management · Experimental design · Field experiments · Implementation $\cdot$ Offender treatment $\cdot$ Session attendance

A growing body of research indicates that prison-based substance-abuse treatment needs to be followed by community treatment in order to obtain optimal outcomes (Hall et al. 2004; Knight et al. 1999; Martin et al. 1999; Wexler et al. 1999). As a result, many states have designed their correctional treatment system to include a continuum of care: prison-based treatment, followed by community-based treatment. To link these two phases of treatment, there is usually a planning and transition process between prison and the community. Depending on the correctional system, referral to community-based treatment consists of either encouraging inmates with drug problems to volunteer for treatment or mandating them to treatment as a condition of parole. Multiple agencies are usually involved in this process. Too often, however, the transition process breaks down, for both individual and systemic reasons.

The promised improvements in offender behavior from continued treatment in the community can be realized only if the transition plan is clear and if prison treatment participants follow through on referrals to community treatment and remain in treatment for a minimum period of time, generally considered to be approximately 3 months (Hubbard et al. 1988; National Institute on Drug Abuse 2006; Simpson et al. 1997a). Failure of parolees to enter community treatment often results in a greater likelihood of relapse to drug use or of rearrest and reincarceration. No-shows and dropouts are particularly problematic in those states where participation in community treatment by parolees is voluntary, since the incentives to enter and remain in treatment are minimal. For example, an evaluation of in-prison drug treatment programs in California indicated that only 34\% of program graduates who had a referral to community-based treatment actually entered treatment following release to parole, and nearly $45 \%$ of those who did enter treatment dropped out within the first 90 days (Prendergast et al. 2005). Even in jurisdictions where community treatment is mandated, attendance may be lax, often because of high parole caseloads, poor coordination between criminal justice and treatment personnel, or low motivation and accountability on the part of the parolee. For whatever reasons, low participation by parolees in community treatment is clearly a barrier to the overall effectiveness and cost effectiveness of offender treatment programs.

Improving the re-entry process from prison treatment to parole treatment was the goal of the Transitional Case Management (TCM) study, which was conducted as part of the Criminal Justice-Drug Abuse Treatment Studies (CJ-DATS) research cooperative funded by the National Institute on Drug Abuse (NIDA). TCM utilized a strengths model of case management (Hall et al. 1999; Siegal and Rapp 1996) to attempt to improve the re-entry process at two levels: (1) by improving the collaboration among correctional and treatment staff, community parole and treatment staff, and other health, mental health, and social service providers, and 
(2) by working directly with the client to develop specific goals and plans for transition to the community and by assisting him/her during the crucial early months in the community to obtain needed services. The rationale and description of the TCM intervention are described in detail elsewhere (Prendergast and Cartier 2008).

As with most, if not all, field studies, TCM faced the problem of varying levels of client participation in the intervention. Poor adherence is an issue in any treatment that is intended to change behavior or is directed toward the management of a chronic problem (McLellan et al. 2000). For example, clients do not take their medications as directed, or they do not attend all of the expected treatment sessions, even though there might be relatively few sessions to attend. Much research is directed toward increasing adherence rates in psychosocial interventions, including those for offenders (Siegal et al. 1993; Sung et al. 2004), either because optimal adherence is necessary for the treatment to have the intended effect or because greater adherence is associated with better outcomes. For case management interventions specifically, regular interaction between the client and the case manager is necessary if the client is to address his/her problems or achieve desired goals. Clients who do not meet with their case manager, or do so irregularly, are less likely to take the steps needed to alleviate their problems or to accomplish their goals. From a research perspective, low participation raises issues of internal validity of the study findings. This paper begins with a review of adherence within field interventions generally, and case management interventions specifically, then summarizes the study design and its implementation, describes the methods for analyzing the data, presents results from the analyses, and discusses the results in terms of their implications for research and practice.

\section{Session adherence in behavioral treatment interventions}

Many intervention protocols for substance abusers, including offenders, include meetings with a counselor, case manager, or other service provider, and study participants are expected to attend all, or at least some, of these meetings. In addition, journals that use the Consolidated Standards of Reporting Trials (CONSORT) guidelines (Moher et al. 2001) require researchers to identify the number of subjects who did and did not complete the intervention, which involves a definition of completion for a given study. At the most basic level, clients cannot benefit from an intervention if they do not participate in its activities, and increasing levels of participation are likely to be related to better outcomes. Many studies are also concerned with a minimum 'dosage' needed to see a treatment effect. For all of these reasons, with the understanding that participation in both the intervention and the research activities is voluntary, researchers seek to keep clients in an intervention as long as possible, track clients' participation in intervention activities, and address the issue of non-participation in analysis.

Of relevance to participation in an intervention such as case management is the issue of dose. While 'dose' in a behavioral intervention cannot be specified with the same precision as with medications, it is nonetheless important to have some estimate of the appropriate dose, since too small a dose may not result in the desired outcomes, while too large a dose may be an inefficient use of resources, or may even 
be harmful. For case management specifically, the question is how many sessions or contacts are needed to produce desired outcomes, given the characteristics and needs of the population and the resources available? This is not to say that dose is the only factor influencing outcomes; other important factors include the specific model of case management used, case manager characteristics, client characteristics, the nature of the alliance that develops between the client and the case manager, and the density and quality of the local service ecology.

Findings from studies that report on session attendance indicate that the level of attendance varies considerably across interventions for substance-abusing clients. The problem is not a new one. Over 30 years ago, in a detailed review of treatment participation in substance abuse and mental health interventions, Baekeland and Lundwall (1975) reported that between $52 \%$ and $75 \%$ of clients in outpatient treatment for alcoholism dropped out before attending four sessions. Nor was the problem confined to substance abuse clients; $31 \%$ to $56 \%$ of patients who were admitted to general psychiatric clinics attended fewer than four times. More recent studies summarized below continue to show low attendance rates. These studies include comparative studies of case management and other behavioral interventions and reports of attendance based on program records.

With respect to formal evaluations, Lidz et al. (1992) reported that, of 287 clients who agreed to participate in a four-session case management intervention to reduce human immunodeficiency virus (HIV) risk behaviors, 36\% had one session with the case manager; of these, $38 \%$ completed all four sessions (14\% of the total). In a case management component of the South Florida AIDS Network provided to clients over several months, $80 \%$ of clients attended only one session (McCoy et al. 1992). Cox et al. (1998) reported that $28 \%$ of long-term public inebriates in an intensive case management intervention had no face-to-face contacts with the case managers, either because they refused services or because they could not be located for services. In comparing dosage of strengths case management across three conditions (delivered within drug treatment programs, delivered by an outside service agency, and delivered by telephone), Huber et al. (2003) reported that, within the first 90 days of the intervention, the mean number of hours of contact ranged from 3.0 to 3.2 and the mean number of sessions attended ranged from 3.5 to 5.7. Jansson et al. (2005) compared routine case management for drug-dependent women and their newborns with intensive case management that involved additional and more frequent contact with the mother and infant. Over the 4-month intervention, women in routine case management attended a mean of 1.6 sessions (range $=0$ to 4 ), whereas those in intensified case management attended a mean of 5.8 visits (range $=0$ to 9 ). A quasi-experimental study of case management for substance-abusing parolees in the San Francisco Bay area found that, over an intervention period of 180 days, $40 \%$ of the parolees reported no more than one inperson or telephone contact with their case manager, and $70 \%$ reported no more than three contacts (Longshore et al. 2005). In a study testing the use of case management to re-enroll discharged methadone clients, Coviello et al. (2006) reported 4.4 contacts between the case managers and clients over a 6-week intervention. A study of enhanced treatment for clients with co-occurring disorders found that the mean [standard deviation (SD)] number of sessions attended out of 12 scheduled was 1.67 (0.95) (Sacks et al. 2008). 
Session attendance has also been examined from records of community agencies or programs. Ventura et al. (1998), in examining attendance at case management sessions among mentally ill persons released from jail, found that, in the first year following release, $27 \%$ of subjects received some case management services, typically fewer than 20 hours over the year. Using program data on admissions to an outpatient substance abuse clinic in Chicago, King and Canada (2004) reported that $36 \%$ of clients attended fewer than five individual therapy sessions. Records data from a multi-site treatment program in Auckland, New Zealand, indicated that $73 \%$ of admissions attended four or fewer sessions and that $40 \%$ attended only a single session (Pulford and Wheeler 2007). A naturalistic evaluation of three cognitivebehavioral programs for parolees in England and Wales found that $46 \%$ of clients attended no sessions, $25 \%$ completed some of the sessions, and $29 \%$ completed all expected sessions (between 20 and 38, depending on the program) (McGuire et al. 2008).

Two observations can be made about these findings. First, the degree of attendance at sessions is difficult to compare across studies, because of the different ways in which attendance is defined and measured. Second, although there are exceptions, clients participate in considerably fewer sessions than the number planned by the researcher; the average number of sessions attended is five or fewer, and a relatively large percentage of clients attend no sessions.

Arguing for a conceptualization of 'dose' that extends beyond session attendance, Huber et al. (2001) present a model of dosage for case management (and, by extension, for other interventions) that consists of four dimensions. Amount refers to the quantity of the activity provided in a single episode (e.g., number of minutes for a session between the client and the case manager). Frequency refers to the rate of occurrence of the activity or the amount of time between activities (e.g., weekly inoffice sessions, monthly telephone calls). Duration refers to the length of time over which the intervention is provided (e.g., 3 months of case management). Breadth refers to the type and number of activities or components that are provided in the intervention (e.g., assessment, counseling, service referrals, or telephone calls that take place within an episode or over the course of the intervention). Within this model, dose can be regarded either as normative, that is, the expected amount, frequency, duration, and breadth (e.g., as specified in the intervention manual), or as descriptive, that is, the actual amount, frequency, duration, and breadth of activities actually received (e.g., as determined by service logs). In the evaluation of an intervention, the actual dose received, averaged over study participants, is of particular interest to determine the integrity or fidelity of intervention implementation, to examine the relationship of dose to study outcomes, and to estimate optimal dosage levels for desired outcomes. In this paper we consider the amount, frequency, and duration of case management sessions for clients in the TCM group (for an analysis of the breadth of case management services received in TCM, see Coen et al., manuscript submitted).

After the degree of compliance with treatment or case management sessions has been considered, it is also useful to determine which client and program factors may predict retention, in order to improve adherence to treatment protocols. Although many studies have reported on a wide variety of client and program variables, a number of researchers have noted that, within the literature on predictors of 
retention, there is considerable inconsistency in the selection of variables and in the variables found to be significant (Hawkins et al. 2008; Stotts et al. 2007). The direction of effect also varies from one study to another for some variables. For example, at the client level, age is commonly found to predict retention, but longer retention is associated in some studies with younger clients (Justus et al. 2006), in others with older clients (Brecht et al. 2005; Mateyoke-Scrivner et al. 2004). Similarly, while women are generally found to stay in treatment longer (Brecht et al. 2005; Hser et al. 2001), in other studies, men stay longer (McCaul et al. 2001). Other client characteristics associated with retention include race/ethnicity (Brecht et al. 2005; Hiller et al. 1998; Mateyoke-Scrivner et al. 2004), marital status (Hiller et al. 1998; Mateyoke-Scrivner et al. 2004); education (Hser et al. 2001; Mattson et al. 1998), and employment (Lang and Belenko 2000; Mattson et al. 1998; Siqueland et al. 2002). Findings on motivation as a predictor of retention are inconsistent (Brocato and Wagner 2008; De Weert-Van Oene et al. 2001), but legal pressure seems to result in longer stay in treatment (Brecht et al. 2005; Hiller et al. 1998; Hser et al. 2001).

Fewer studies have examined program-level predictors of retention. In an analysis of the effects of program factors on retention in drug treatment programs (residential, outpatient, methadone), Hser et al. (2001) found that better retention (in at least one of the modalities) was associated with programmatic focus, case load, an emphasis on group therapy, and percentage of staff in recovery. Researchers in Project MATCH (matching alcoholism treatments to client heterogeneity) reported that clients who were promptly admitted to treatment (following study recruitment) attended a greater proportion of sessions (Mattson et al. 1998). De Weert-Van Oene et al. (2001) found that helping alliance was a strong predictor of treatment retention; one component of helping alliance (cooperation with the therapist) was positively associated with retention, while helpfulness of the therapist was negatively associated with retention, possibly because clients with greater confidence in their ability to deal with their drug problems left treatment early. Counselor or therapist characteristics have also been found to be associated with treatment retention (Hser et al. 2001; Sterling et al. 2002).

\section{Research questions}

This paper provides an examination of the pattern of attendance by TCM clients at scheduled community case management sessions, with particular attention to the following questions: How many scheduled sessions did clients attend? How many hours of contact were there between the client and the case manager? Which client and/or case manager characteristics were associated with attendance? What was the pattern of attendance over the course of the intervention?

\section{Study design and procedures}

The TCM study was a multi-site randomized field trial of strengths-based case management for use with drug-abusing parolees who were completing prison-based 
treatment and transitioning to parole supervision in the community. The study conditions were the TCM intervention (described below) or standard referral. Participants in both groups received standard planning and referral services that were available to parolees within their respective state correctional systems, and participants in both groups received a referral to community-based treatment that was at least partly funded by local or state dollars. In addition, during the month prior to release from prison, participants in both groups viewed a professionally produced motivational video that emphasized the importance of community treatment for offenders. Four CJ-DATS research centers were involved, each of which collaborated with criminal justice and treatment partners in four states.

\subsection{Description of TCM intervention}

As adapted for a parolee population, the TCM intervention included three phases, the first two of which occurred in prison and the third in the community (Prendergast and Cartier 2008):

- Strengths assessment. At the first session, conducted approximately 2 months prior to release, the case manager met with the client to complete a strengths assessment that identified strengths, accomplishments, resources, and goals and to develop plans for addressing immediate needs upon release, including enrollment in treatment.

- Conference call. Approximately 1 month prior to release, a conference call took place that included the client and the client's treatment, supervision, and family support network. The conference call was intended to provide an opportunity for the client and the other people involved in the transition from prison to community to discuss the discharge plan, to provide encouragement to attend community treatment, and to identify sources of community support.

- Community sessions. In the community, the case manager met with clients weekly for 3 months, followed by 3-monthly follow-up contacts for any clients needing additional help. The focus of the weekly sessions was to encourage clients to enter and remain in substance abuse treatment and to obtain other services and assistance to address their goals and needs. The analyses presented below focus on attendance at the 12 weekly community sessions.

\subsection{Case managers: characteristics and training}

Across the sites, 12 case managers delivered the intervention over the course of the study. Of these, seven were women and five were men. The average age was 39.6 years (range 31-55 years). By ethnicity, six were African American and six were White. Seven had a bachelor's degree and five a master's degree, with three also having counseling certification. Seven had some experience as case managers before becoming involved in the TCM study. All sites except one experienced turnover in the case manager position during the study.

To facilitate fidelity to TCM, case managers received training and supervision during the study. A comprehensive three-and-a-half day training was conducted prior to study initiation by Dr. James Hall, whose Iowa Case Management Project model 
of strengths case management was modified for this study. The training included both clinical and research topics, including review of the TCM study and use of study instruments; an introduction to strengths case management; details on conducting the intervention; and clinical issues in client-case manager interaction. Half way through implementation, Dr. Hall conducted 3-hour refresher training for the case managers via a conference call. To train new case managers who were hired later in the study, the sites used printed materials and a video of the initial training. Once the study was underway, conference calls that focused on case managers' questions and issues were conducted bi-weekly initially and then monthly. Additionally, site-specific supervision of case managers was conducted regularly. The caseload for each case manager was expected to be 15, although it varied over time, being smaller when the study was beginning and winding down, and reaching 20 at other times.

\subsection{Recruitment}

Subjects for the study were recruited from prison-based treatment programs in four states. The number of prisons for recruitment across states varied from 3 to 15 . Inmates (men and women) were eligible to participate in the study if they were aged 18 years or older, were enrolled in a treatment program within a correctional institution, had a referral to a community-based drug abuse treatment program following release to parole, were within approximately 3 months of release, and were being released to city or county where TCM case managers were located. ${ }^{1}$ Even if inmates met these criteria, they were excluded from participation if they had a referral to formal case management services not part of the TCM study (e.g., mental health services), were a registered sex offender, had parole requirements that would prevent study participation (e.g., Immigration and Customs Enforcement hold for deportation), or were unable to provide informed consent. In each of the participating states participation in community treatment was mandated, although the degree to which the mandate was enforced varied from state to state.

Trained research staff from the participating research centers contacted the inmates individually, met with them in a private room, confirmed eligibility, described the study and informed consent procedures, and answered any questions. The baseline interview occurred at the time of consent or soon after, usually within 1 week. After completing the baseline interview, clients were randomly allocated to the TCM group or to the standard referral group. Study procedures and informed consent forms received approval from the CJ-DATS Steering Committee and from the Institutional Review Board at each of the participating research centers. A data and safety monitoring board conducted a quarterly review of study implementation and adverse events. In accordance with human subject requirements, participation in research interviews and attendance at TCM sessions was voluntary.

The four research centers recruited 812 clients, with each center contributing approximately 200 clients. By design, $25 \%$ of the sample consisted of women.

\footnotetext{
${ }^{1}$ In one of the states a small number of the study participants were under probation supervision upon release from the institution. For convenience, the criminal justice status of the sample is referred to as 'parolee' throughout the paper.
} 
Initially, 411 study participants were assigned to the TCM group and 401 to the standard referral group. One client assigned to the standard referral group mistakenly ended up in the TCM group. At the time of recruitment, all clients assigned to the TCM group were scheduled for parole within approximately 3 months to a county where they could participate in the TCM study, but subsequently 25 of them either had their release date changed such that they would not be paroled in time to receive TCM services or had their parole location changed to a county or state where TCM services were not provided. These clients, who did not have the opportunity to participate in case management sessions in the community, were excluded from analyses, leaving a baseline sample of 386 in the TCM condition (some analyses include a somewhat smaller sample due to missing data).

\subsection{Analyses}

To document session attendance, case managers completed forms for each scheduled session with a client, whether it happened or not, consisting of closed-ended responses to questions about which of the various activities of the case management protocol were completed for each session. For purposes of this paper, the forms provided information on which sessions were attended and the duration of each session. These variables are presented as descriptive statistics.

The next stage of analysis consisted of attempting to identify possible predictors of attendance at case management sessions. Preliminary analysis indicated that there was substantial variation among case managers in the average number of sessions that their clients completed. Therefore, to adjust for a 'case manager effect,' which would lead to correlated unobserved factors common to all the clients of a particular case manager, we used mixed Poisson regression models to analyze predictors of the number of sessions attended. The Poisson distribution is appropriate for count variables (Greene 1993). In this analysis, clients were the level-1 units and case managers the level-2 units.

In the analysis the intercept was modeled as a random effect. Thus, case manager intercepts were allowed to vary randomly around the overall intercept. Predictors (discussed below) were modeled as fixed effects. The estimation method was residual pseudo-likelihood, with a Taylor series expansion that was specific to subject (i.e., to case manager). The estimator chosen for the covariance matrix of the fixed-effects parameters was asymptotically consistent and corrected for bias; all test statistics and standard errors were adjusted accordingly. The relatively stable Cholesky root algorithm was chosen for creating and solving the mixed model equations. An unstructured variance-covariance matrix using the Cholesky root was specified (SAS Institute 2006).

Predictors consisted of client characteristics from the baseline interview and case manager characteristics coded by project staff. Client characteristics included sociodemographic measures (age, ethnicity, gender, marital status), measures of socioeconomic position (number of years of schooling completed and recent employment status), number of lifetime arrests, the Texas Christian University (TCU) drug screen (dichotomized at the clinical cut-off point of 3 or above) to indicate severity of substance use (Simpson et al. 1997b), and the desire for help subscale of the TCU client evaluation of self at intake (Simpson and Joe 1993), 
dichotomized at the median, as a measure of treatment motivation. Case manager characteristics included gender, ethnicity, age, and whether the case manager held a credential or other certification specific to substance abuse counseling. Continuous predictors were centered at the mean number of sessions attended by the clients of each case manager. This centering made these into level-2 (case manager level) variables, whose effects were interpreted as effects on within-case manager variation in the number of sessions (Singer 1998). Sample size for the mixed Poisson regression was 370 . Of the 382 clients available for analysis, eight had missing case manager information, and an additional four had missing values on other analysis variables, leaving 370 cases for the mixed Poison regression analysis. Analyses were conducted using SAS/STAT ${ }^{\circledR}$ version 9.1.3 PROC GLIMMIX (SAS Institute 2006).

Finally, to identify patterns of participation in case management sessions, we analyzed the attendance data using Nagin's semiparametric group-based method for defining trajectories of behavior over time (Nagin 1999; Nagin and Land 1993). The 12 dependent variables in the model were binary indicators of whether or not a TCM client attended a given session, in sequence. The data were analyzed using a logistic distribution that allowed for quadratic parameters to form nonlinear curves. The Bayes Information Criterion (BIC) statistic and substantive criteria were used to select the number of trajectories for the final model. Once the trajectories had been identified and described, we compared client and case manager characteristics across trajectories using chi-square for categorical variables and analysis of variance (ANOVA) for continuous variables.

\section{Results}

Table 1 lists the characteristics of clients in the TCM condition. The reference point for variables such as employment and education was the time before the arrest that resulted in the current incarceration. (Clients in the control condition did not differ significantly from those in the treatment condition in baseline characteristics, except for race/ethnicity, where TCM clients were more likely than control clients to be White.) The client profile was typical of that found in research samples of substanceabusing parolees, except that, by design, approximately $25 \%$ were women.

The results for session attendance, overall and for each site, are shown in Table 2. Overall, nearly $97 \%$ of the clients completed the strengths assessment. In the large majority of cases, the strengths assessment occurred in prison shortly after the participant's recruitment into the study, but, in a few cases, where the client was released from prison earlier than expected, the case manager completed the strengths assessment with the client at the initial community session.

Across all sites, approximately $72 \%$ of the clients participated in the conference call. Scheduling the calls often proved difficult. In some cases, inmates were paroled before the call could take place. In other cases, institutional staff or parole officers declined to participate in the conference call. Equipment malfunction prevented some calls from occurring.

The intervention protocol called for 12 weekly sessions between the case manager and the client, although additional sessions could occur if needed. When it became clear that attendance at the weekly sessions was a problem, we set four sessions as 
Table 1 Baseline characteristics of clients in the TCM group [percentage or mean (SD)]

\begin{tabular}{|c|c|}
\hline Variable & TCM Group $(N=382)$ \\
\hline Age & $33.5(8.9)$ \\
\hline \multicolumn{2}{|l|}{ Race } \\
\hline Hispanic/Latino & 14.9 \\
\hline African American/Black & 29.1 \\
\hline White & 50.0 \\
\hline Other & 6.0 \\
\hline \multicolumn{2}{|l|}{ Gender } \\
\hline Male & 75.1 \\
\hline Female & 24.9 \\
\hline \multicolumn{2}{|l|}{ Marital status } \\
\hline Never married & 58.5 \\
\hline Legally or living as married & 15.8 \\
\hline Separated/divorced/widowed & 25.7 \\
\hline Homeless & 5.8 \\
\hline Education (highest grade completed) & $10.8(1.9)$ \\
\hline Employment (worked in past 6 months) & 47.4 \\
\hline Times in jail or prison (lifetime) & $17.4(21.7)$ \\
\hline Months incarcerated (lifetime) & $67.0(54.4)$ \\
\hline Drug-related arrests (lifetime) & $13.3(14.2)$ \\
\hline Any arrests (lifetime) & $21.3(23.3)$ \\
\hline \multicolumn{2}{|l|}{ Primary drug } \\
\hline Opiates & 10.6 \\
\hline Cocaine/crack & 23.7 \\
\hline Marijuana & 15.2 \\
\hline Alcohol & 20.5 \\
\hline Methamphetamine/amphetamine & 25.5 \\
\hline Other (excluding tobacco) & 1.1 \\
\hline Dependence/abuse & 83.5 \\
\hline Desire for help & 58.8 \\
\hline
\end{tabular}

the minimum desired level of participation. Four community sessions was selected after discussion with experts in case management and after a review of studies of brief interventions, which indicated that four sessions could be expected to have a positive effect on outcomes. Overall, $13 \%$ of the clients attended no sessions, $18 \%$ attended between one and three sessions, and 69\% attended four or more community sessions. The average number of community sessions attended was $5.7(\mathrm{SD}=3$.).

Table 3 presents the percentage of clients who attended each of the 12 community sessions. Overall, 70\% attended the first session, with the percentage steadily declining to just under one-half by the 12th session. The pattern of session attendance was similar across the individual sites.

Session attendance as defined above means only that the client and case manager met, either in person or by telephone. Within the 'dosage' model of Huber et al. (2001), the amount or quantity of case management is also important. Calculations 
Table 2 Attendance at scheduled TCM sessions (in percent) (excludes 25 inmates originally assigned to the TCM group but who were not released in time to participate in community case manager sessions or who were paroled to a county or state where TCM services were lot available)

\begin{tabular}{llllll}
\hline Program & $\begin{array}{l}\text { Strengths } \\
\text { Assessment }\end{array}$ & $\begin{array}{l}\text { Conference } \\
\text { Call }\end{array}$ & $\begin{array}{l}\text { Community } \\
\text { Sessions (None) }\end{array}$ & $\begin{array}{l}\text { Community } \\
\text { Sessions (1-3) }\end{array}$ & $\begin{array}{l}\text { Community } \\
\text { Sessions ( } \geq 4)\end{array}$ \\
\hline A (94) & 98.9 & 74.5 & 12.8 & 21.3 & 66.0 \\
B (102) & 93.1 & 54.9 & 20.6 & 20.6 & 58.8 \\
C (92) & 94.6 & 87.0 & 15.2 & 10.9 & 73.9 \\
D (94) & 100.0 & 71.3 & 2.1 & 18.1 & 79.8 \\
Total (382) & 96.6 & 71.5 & 12.8 & 17.8 & 69.4 \\
\hline
\end{tabular}

from the case manager forms indicated that the average session lasted 35 minutes and that, across all sessions, the average amount of time spent between the client and the case manager was 181 minutes; if clients who attended no sessions were removed from the calculation, the average increased to 184 minutes. The TCM protocol did not specify a minimum amount of contact time per session.

Half way into the study, case managers were asked to indicate reasons why clients attended fewer than four sessions. Since case managers responded only for clients who had attended fewer than four sessions and some case managers had left the project and could not complete the forms, data were available on 91 clients in the TCM group. Their responses, accumulated through to the end of the study, are shown in Table 4. The most common reason for limited attendance (46\%) was that the case manager was unable to contact the client to schedule the first session or to follow-up on missed sessions. Although contact information was obtained at the strength assessment session, upon release parolees may have inadvertently or deliberately failed to inform the case manager about a change in telephone number

Table 3 Percentage of TCM clients attending each community session

\begin{tabular}{llllll}
\hline $\begin{array}{l}\text { Community } \\
\text { Session }\end{array}$ & $\begin{array}{l}\text { Program A } \\
(n=98)\end{array}$ & $\begin{array}{l}\text { Program B } \\
(n=99)\end{array}$ & $\begin{array}{l}\text { Program C } \\
(n=91)\end{array}$ & $\begin{array}{l}\text { Program D } \\
(n=94)\end{array}$ & $\begin{array}{l}\text { Total } \\
(n=382)\end{array}$ \\
\hline 1st & 63.3 & 59.6 & 69.2 & 90.4 & 70.4 \\
2nd & 55.6 & 55.6 & 63.2 & 80.9 & 63.6 \\
3rd & 54.1 & 52.9 & 60.1 & 74.5 & 60.2 \\
4 th & 50.5 & 52 & 57.4 & 70.7 & 57.5 \\
5 th & 49.2 & 52.1 & 58 & 66.6 & 56.3 \\
6 th & 47.6 & 51.9 & 56.6 & 63.5 & 54.8 \\
7 th & 46.2 & 51.7 & 55.1 & 60.8 & 53.3 \\
8 th & 45 & 50.9 & 54.1 & 58 & 51.9 \\
9 th & 44.1 & 50.1 & 53.1 & 55.6 & 50.6 \\
10 th & 42.7 & 49.2 & 52.3 & 53.9 & 49.4 \\
11 th & 41.7 & 48.9 & 50.9 & 52.7 & 48.5 \\
12th & 41.2 & 48.5 & 50.4 & 51.5 & 47.8 \\
\hline
\end{tabular}


Table 4 Reasons (from case managers) for TCM clients attending fewer than four community sessions

\begin{tabular}{lll}
\hline Reasons & Number $(n=91)$ & Percentage \\
\hline Client request & 15 & 16.5 \\
No need for services & 6 & 6.6 \\
No time to participate & 6 & 6.6 \\
Unspecified & 3 & 3.3 \\
Client incarcerated & 22 & 24.0 \\
Client known to have relapsed, no further participation & 6 & 6.6 \\
Client had prolonged hospitalization & 1 & 1.0 \\
Client had died & 2 & 2.0 \\
Reason unspecified/unknown & 3 & 3.0 \\
Case manager unable to contact & 42 & 46.0 \\
No telephone & 3 & 3.3 \\
Moved, no forwarding address & 10 & 11.0 \\
Unspecified & 29 & 32.0 \\
\hline
\end{tabular}

or address. Parolees who absconded would be reluctant to maintain contact with the case manager, despite assurances that the case manager would not provide any information to criminal justice staff. The second most common reason for attending fewer than four sessions (24\%) was incarceration. One in six of the clients (16\%) indicated that they no longer wanted to participate in case management services, either because they had no further need of such services or because they had no time to participate.

Mixed Poisson regression analysis was used to determine which client or case manager characteristics predicted the number of sessions attended (Table 5). Case manager characteristics were more important than client characteristics in predicting the session attendance. African American case managers had clients who attended more sessions than case managers who were White. Clients of case managers who were older attended more sessions than clients whose case managers who were younger. At the client level, clients who were older attended significantly more sessions than did younger clients.

The final question examined had to do with identifying patterns (trajectories) of session attendance over time and determining whether any client or case manager characteristics were associated with the identified trajectories. Nagin's semiparametric group-based method for defining behavior over time (Nagin 1999; Nagin and Land 1993) was used to identify trajectories of session attendance (see Addendum for statistical model). In the selection of the number of trajectory groups, lower BIC values generally indicate a better model fit. For the attendance trajectories, although the three-group model did not fit quite as well as the four-group model (BIC $=-2,448$ vs. $-2,434)$, the four-group model produced a group with only ten people, suggesting that it reflected idiosyncrasies in the data. The three-group model is shown in Fig. 1. Clients in the low attendance group, comprising one-fourth (24.8\%) of the sample, exhibited low levels of attendance from the beginning and, by the fourth session, were unlikely to attend any sessions, for a mean of $0.64(\mathrm{SD}=0.74)$ 
Table 5 Mixed Poisson regression of number of sessions on predictors $(n=370)$ (intercept modeled as a random effect)

\begin{tabular}{|c|c|c|}
\hline Fixed Effects and Covariance Parameter Estimate & Estimate & Standard Error \\
\hline $\operatorname{Age}^{a}$ & $0.01 * *$ & 0.003 \\
\hline Male (vs. female) & -0.03 & 0.07 \\
\hline White (vs. all other) & 0.05 & 0.06 \\
\hline Married (yes/no) & -0.03 & 0.09 \\
\hline Highest grade completed ${ }^{a}$ & -0.01 & 0.01 \\
\hline Worked in past 6 months (yes/no) & 0.05 & 0.05 \\
\hline Number of lifetime arrests ${ }^{\mathrm{a}}$ ('Winsorized' at 100) & 0.00 & 0.00 \\
\hline Dependence/abuse (yes/no) & 0.18 & 0.13 \\
\hline Desire for help (high vs. low) & 0.03 & 0.11 \\
\hline Case manager is male (vs. female) & -0.29 & 0.16 \\
\hline Case manager is Black/African American (vs. White) & $0.37 * * *$ & 0.11 \\
\hline Case manager age & $0.02 * *$ & 0.01 \\
\hline Case manager has credential (yes/no) & 0.14 & 0.19 \\
\hline Intercept & 0.54 & 0.37 \\
\hline Covariance parameter estimate (for the intercept) & $0.19^{*}$ & 0.07 \\
\hline
\end{tabular}

${ }^{\mathrm{a}}$ Centered around case manager mean

$* P<0.05 ; * * P<0.01 ; * * * P<0.001$

TCM: Percentage completing a session by Week

Proportion completing

3-group quadratic logit Model

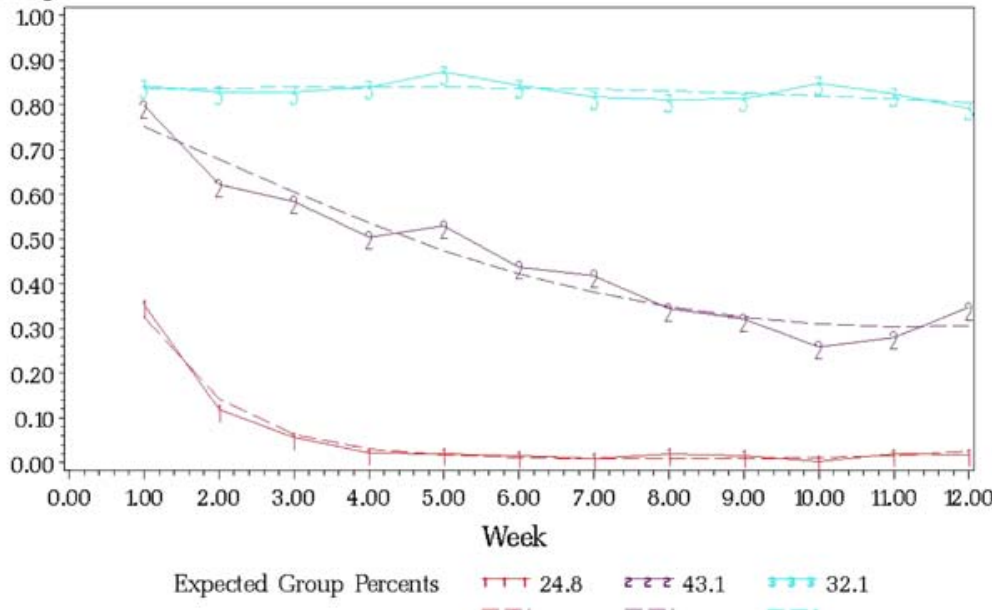

Group 1 = Low Attendance Group $2=$ Moderate Attendance Group 3 = High Attendance

Fig. 1 Results of trajectory analysis of number of community sessions attended. Group 1 low attendance; group 2 moderate attendance; group 3 high attendance 
sessions. Clients in the moderate attendance group (43.1\%) were highly likely to attend the first session, but then steadily declined in their attendance at subsequent sessions, with a slight increase for the last two sessions, for a mean of 5.34 (SD= 1.54) sessions. The high attendance group (32.1\%) consisted of clients who attended nearly all the sessions, for a mean of $10.01(\mathrm{SD}=1.33)$ sessions.

Table 6 presents the results of the analysis to examine any differences across trajectory groups in terms of client and case manager characteristics. Few characteristics emerged as being significant. Among client characteristics, only age was significant, with older clients being more likely to be in the high attendance group. Also, only one of the case manager characteristics was significant. Contrary to what might be expected, clients whose case managers had credentials were less likely to be in the high attendance group.

\section{Discussion}

Clients in the TCM group attended fewer than half of the 12 scheduled case management sessions, an average of 5.7 sessions. Approximately $13 \%$ attended no session, and another $18 \%$ attended one to three sessions. Still, the $69 \%$ who attended four or more sessions was higher than the level of attendance reported in many of the behavioral interventions reviewed above, although strict comparison across studies and programs is not possible. TCM clients received, on average, approximately 3 hours of case management across all sessions. Using a similar strengths case management model with substance abuse clients, Huber et al. (2001) also found that, over the first 90 days of the intervention, the average contact time was 3 hours. Most clients attended the first community session, but then participation gradually declined, to fewer than one-half attending the 12th session.

Given the population being served by TCM, the reasons for limited attendance should not be surprising. Nearly one-quarter (24\%) of the TCM clients were reincarcerated at some time during the intervention. For clients who attended fewer than four sessions, in $46 \%$ of the cases the case manager had no working telephone number or address to contact the client. Case management services were ended by $16 \%$ of clients, who said that they had no need of further services or that they did not have time to participate. Since attendance at case management sessions was voluntary, the case manager had little leverage with those clients who had no need or desire to attend.

In a regression analysis to determine which client and case manager characteristics were associated with session attendance, characteristics of the case managers were somewhat more important than client characteristics. Clients who attended more sessions were more likely to have case managers who were older or who were African American than clients who attended fewer sessions. It might be expected that the case manager characteristics had an effect on attendance, as has been found in other studies (Hser et al. 2001; Sterling et al. 2002), but, for the purpose of guiding hiring decisions in the future, the demographic and experience variables that we included in the analysis might not be all that useful. More clinically relevant variables were not available for analysis. The only client-level characteristic that predicted session attendance was age, with older clients attending more sessions than younger clients. 
Table 6 Client and case manager characteristics by trajectory group [percentage or mean and (SD)]

\begin{tabular}{|c|c|c|c|c|}
\hline Variable & $\begin{array}{l}\text { Group } 1 \\
(n=95)\end{array}$ & $\begin{array}{l}\text { Group } 2 \\
(n=161)\end{array}$ & $\begin{array}{l}\text { Group } 3 \\
(n=126)\end{array}$ & $\begin{array}{l}\text { Total } \\
(n=382)\end{array}$ \\
\hline \multicolumn{5}{|l|}{ Client characteristics } \\
\hline Number of community sessions completed ${ }^{* *}$ & $0.64(0.74)$ & $5.34(1.5)$ & $10.01(1.3)$ & $5.7(3.8)$ \\
\hline Age* & $32.0(9.5)$ & $33.1(8.5)$ & $35.1(8.6)$ & $33.5(8.9)$ \\
\hline \multicolumn{5}{|l|}{ Race } \\
\hline Hispanic/Latino & 16.8 & 14.9 & 13.5 & 14.9 \\
\hline African American/Black & 33.7 & 29.8 & 24.6 & 29.1 \\
\hline White & 41.1 & 50.3 & 56.4 & 50.0 \\
\hline Other & 8.4 & 5.0 & 5.6 & 6.0 \\
\hline Male & 76.8 & 75.8 & 73.0 & 75.1 \\
\hline \multicolumn{5}{|l|}{ Marital Status } \\
\hline Never married & 66.3 & 53.4 & 59.2 & 58.5 \\
\hline Legally or living as married & 15.8 & 16.8 & 14.4 & 15.8 \\
\hline Separated/divorced/widowed & 17.9 & 29.8 & 26.4 & 25.7 \\
\hline Homeless & 7.3 & 5.2 & 5.7 & 5.8 \\
\hline Education (highest grade completed) & $10.7(2.0)$ & $10.9(1.8)$ & $10.8(2.1)$ & $10.8(1.9)$ \\
\hline Employment (worked in past 6 months) & 52.6 & 43.5 & 48.4 & 47.4 \\
\hline Times in jail or prison (lifetime) & $14.2(19.1)$ & $19.24(23.9)$ & $17.4(20.4)$ & $17.4(21.7)$ \\
\hline Months incarcerated (lifetime) & $66.1(56.6)$ & $69.02(53.0)$ & $65.2(54.9)$ & $67.1(54.4)$ \\
\hline Drug-related arrests (lifetime) & $10.5(12.5)$ & $13.7(14.6)$ & $14.9(14.8)$ & $13.3(14.2)$ \\
\hline Number of arrests (lifetime; 'Winsorized' at 100) & $18.4(21.9)$ & $22.8(24.8)$ & $21.6(22.1)$ & $21.3(23.3)$ \\
\hline \multicolumn{5}{|l|}{ Primary drug } \\
\hline Opiates & 10.6 & 9.5 & 12.1 & 10.6 \\
\hline Cocaine/crack & 20.2 & 22.8 & 27.4 & 23.7 \\
\hline Marijuana & 21.3 & 12.0 & 14.5 & 15.2 \\
\hline Alcohol & 25.5 & 18.4 & 19.4 & 20.5 \\
\hline Methamphetamine/amphetamine & 18.1 & 30.4 & 25.0 & 25.5 \\
\hline Other (excluding tobacco) & 1.1 & 1.9 & 0.0 & 1.1 \\
\hline Dependence/abuse & 79.0 & 81.3 & 89.7 & 83.5 \\
\hline Desire for help & 50.5 & 61.3 & 61.9 & 58.8 \\
\hline \multicolumn{5}{|l|}{ Research center*** } \\
\hline Program A & 22.1 & 32.3 & 16.7 & 24.6 \\
\hline Program B & 40.0 & 14.3 & 32.5 & 26.7 \\
\hline Program C & 19.0 & 24.8 & 27.0 & 24.1 \\
\hline Program D & 19.0 & 28.6 & 23.8 & 24.6 \\
\hline \multicolumn{5}{|l|}{ Case Manager Characteristics ${ }^{\mathrm{a}}$} \\
\hline Age & $40.0(8.7)$ & $42.4(9.0)$ & $42.9(9.2)$ & $42.0(9.0)$ \\
\hline African American & 61.1 & 56.9 & 62.9 & 59.9 \\
\hline Male & 44.4 & 33.1 & 37.1 & 37.2 \\
\hline With credentials* & 22.2 & 28.8 & 13.7 & 22.2 \\
\hline
\end{tabular}

$* P<0.05 ; * * P<0.001$

${ }^{a}$ Based on 12 case managers who had more than one client and complete data. These 12 case managers had a total of 374 clients (90 in group 1, 160 in group 2, and 124 in group 3) 
The pattern of attendance across time (trajectories) is probably what would be expected. One group of clients consistently met with the case manager at all or nearly all of the sessions. Another group steadily declined in attendance. The third group attended few or no sessions. In examining client and case manager characteristics associated with these three trajectory groups, we found that, again, only age was a significant client characteristic. Unexpectedly, a lower percentage of clients whose case managers had credentials were in the high attendance group than in the other two trajectory groups. The possession of credentials might have been confounded with some other variable(s) that we did not measure. For both analyses, it was surprising that, besides age, client-level characteristics that were identified in previous studies were not associated with attendance based on this sample. However, as noted earlier, there is considerable inconsistency in whether certain client characteristics are found to be significant or not and even in the direction of the effect.

\subsection{Clinical implications}

Clients do not participate in case management in a straightforward manner. They miss sessions, they reschedule sessions, they ask for more sessions. This suggests that there is a need for flexibility both in how 'adherence' is measured in case management studies and in how case management interventions are designed and implemented. We may be too rigid in our expectations of how clients would actually utilize case management services, especially those in the criminal justice system.

Parolees face numerous challenges when they enter the community in order to avoid being returned to prison. Depending on the jurisdiction, level of supervision, and personal circumstances, these may include meeting regularly with the parole officer, finding housing, securing employment, paying restitution, completing court-mandated anger management or domestic violence classes, attending substance abuse treatment, re-establishing family relationships, avoiding criminal associates, engaging in prosocial leisure or recreational activities, attending to medical problems, and maintaining prescribed psychiatric medications. If attending case management sessions is not required by parole conditions, the incentives for meeting with the case manager are low, particularly for parolees who are still involved in a criminal lifestyle.

Given the minimal pressures on parolees to participate in case management, and the competing demands on parolees' time, the case manager or the agency providing case management needs to consider steps to increase attendance at case management sessions. Lefforge et al. (2007) reviewed research-based interventions for improving session attendance in mental health and substance abuse settings, with an emphasis on attendance at the initial session. The methods included scheduling appointments as soon as possible after initial contact with the client, reminding clients of appointments through letters and telephone calls, establishing commitment contracts with clients, providing clients with incentives for attendance, and addressing obstacles faced by clients in attending sessions. Obstacles to attendance might include the location of the case manager's office, the convenience of office hours for clients, the availability of the case manager by telephone or email, and the ability and willingness of the case manager to meet with clients outside of the office.

When implementation monitoring indicated that attendance at community case management sessions was a problem, the research centers participating in the TCM 
study identified specific activities that case managers could take to improve attendance and developed procedures to document activities. Case managers were expected to undertake and document the following activities to re-engage clients who had missed two consecutive sessions: write letters; make telephone calls during work hours and during evenings and weekends; attempt to locate clients in the community (home, parole office, etc.); and conduct database searches for contact information. The case manager documented each activity for each client and reported aggregate results monthly to the lead center of the TCM study. How effective were these efforts to re-engage clients? When this heightened activity began (in June 2006), 67\% of TCM clients had attended four or more sessions. At the end of the intervention (December 2007), the percentage was 69\%, with the percentage for the intervening months never exceeding $70 \%$. It appears that the activities undertaken to improve session attendance did little to increase attendance above what it was at the beginning of these efforts, although they may have prevented a decline in attendance over time. It should be recalled that participation in case management was voluntary and that $24 \%$ of the clients were reincarcerated before the end of the 12-week intervention.

Could additional efforts, beyond what the case managers did, have produced an ever greater increase in attendance? The main issue becomes whether efforts to increase attendance, such as those conducted within the context of a research study, could (would) be carried out by local jurisdictions that might wish to use the TCM model with their parolees. For TCM, we developed what we believed was a reasonable balance between the time spent maximizing attendance and the time spent addressing client needs. In research terms, we believed that the study should be carried out with as much attention to generalizability as to internal validity. In clinical terms, practitioners would likely adopt another intervention that could be implemented with more reasonable cost and effort. An alternative strategy, based on the assumption that most clients would attend only a few sessions, would be to concentrate case management services in the early sessions, possibly increasing the length and/or frequency of sessions during the first few weeks, with later sessions tapering to a less intense schedule.

\subsection{Research implications}

The CONSORT guidelines (Moher et al. 2001) are largely based on the medical model in which a minimal dose of medication or treatment is expected, and the researcher is asked to indicate the percentage of clients who complied with the treatment protocol. Does case management fit this model? Too much appears to be happening in case management (at least in TCM) to set rigid and arbitrary definitions/criteria of what constitutes 'adherence.' While some minimal level of service may be necessary, it greatly simplifies what happens in case management. A full analysis needs to take into account both scheduled and unscheduled sessions; inoffice, out of office, and telephone contacts with the client; contacts with persons involved in the client's goals plan; the pattern of utilization of case management services (e.g., full vs. sporadic engagement, early vs. late engagement); and the degree to which clients 'need' case management services beyond a certain point. It is doubtful that a single definition (session attendance cut point) could capture the complexity of a case management study in real world settings. 
To monitor the implementation of a field study and assess the therapeutic integrity of the intervention, the researcher establishes a level of participation that defines 'adherence.' As the study proceeds, monitoring bodies will expect the researcher to meet the adherence goals and urge or require efforts to increase adherence if the goals are not being met. In the extreme case, where adherence continues to fall far short of the goals, the study might be stopped. In addition, in terms of the internal validity of the study, the adherence goals determine whether the intervention has integrity with respect to client participation. An assumption about an adherence goal is that clients who do not attend the minimum number of sessions will not benefit from the intervention. In other words, following the medical model, a minimum dosage of treatment is assumed to be needed in order for the benefits of the intervention to be realized. With respect to interventions for offenders, in particular a case management intervention, this assumption might lead to the conclusion that clients who do not meet adherence goals are 'treatment failures.' An alternative assumption is that some clients attend the intervention until their needs are met and then stop attending or attend more sporadically. On this assumption, those who attend fewer than the defined minimum number of sessions may be considered 'treatment successes.' In explaining the decline in attendance in their case management intervention (also called transitional case management) for high-risk clients, Lidz et al. (1992: 129) write:

Many clients came to TCM for help of a specific kind, such as a letter of referral to an agency distributing free food, placement in a shelter or detoxification program, or an appointment at a medical clinic. . . . If their specific needs were addressed in one or two sessions, they often did not return. In many cases, dropping out reflected a judgment, even if unwise, that urgent needs had been met and TCM was no longer necessary. For other clients, the records indicate the case manager's agreement that reasonable goals set in the initial needs assessment had been achieved after two or three sessions. In these cases, early termination was made or the case manager informally agreed that the client had completed TCM unless an unexpected need arose.

From this perspective, specifying a particular 'dose' of case management in terms of a minimum number of sessions fails to capture the complex nature of case management by applying a medical model where a needs-based model may be more relevant. Indeed, the philosophy of strengths case management is opposite to that of the medical or disease model of substance abuse disorders, with its emphasis on pathology, illness, and clinician focus. The application of a needs-based model requires careful assessment of needs upon the client's entrance to case management and a system for documenting the type, frequency, and outcome of services for identified needs. Further research would be useful in clarifying the appropriate criterion for establishing an appropriate dose for case management for a particular population of clients.

The fact that 25 offenders recruited into the TCM group were not released to parole and never had the opportunity to participate in the community case management sessions and that, of those who were released to parole, $13 \%$ attended no sessions and $18 \%$ attended between one and three sessions, presents problems for an intent-to-treat (ITT) analysis. In the analyses reported here, because our focus was 
on community case management sessions, we excluded those who were never released from prison, but we included all others. ITT analysis is a conservative approach to estimating causal effects in that it provides an unbiased estimate of the effect of assignment rather than treatment. However, even well-designed studies often suffer from treatment dilution (i.e., clients assigned to treatment do not receive treatment) or treatment migration (i.e., clients in the control group receive the treatment) (Gartin 1995). Under these conditions, an ITT approach does not answer the clinical question about treatment: What outcomes can one expect from clients who actually received at least some amount of treatment? The ITT analysis will provide an unbiased estimate of the effect of assignment, but it will generally be an underestimate of the effect of receiving treatment, since treatment effects (as opposed to assignment effects) are diluted by non-attendance among clients in the treatment group and crossovers among clients in the control group. The issue of non-compliance is often addressed by comparing treatment compliers with the full comparison group, but this provides a biased estimate of the treatment effect because of selection bias. Techniques to estimate unbiased treatment effects in the face of noncompliance is beyond the scope of this paper, but, to address this problem, intervention researchers should consider supplementary approaches to ITT analyses, such as the use of instrumental variables (Angrist 2006), principal stratification (Barnard et al. 2003), and complier average causal effects (CACE) (Little and Yau 1998).

In summary, field studies of correctional treatment interventions usually experience lower rates of client participation in scheduled sessions than are planned-often much lower. This study provided detailed information on session attendance by parolees in a randomized study of case management for parolees reentering the community. Out of the scheduled 12 community sessions, $13 \%$ of parolees in the treatment condition attended no sessions and $69 \%$ attended four or more. These percentages are not atypical of other case management studies.

Although researchers (and the bodies that monitor their studies) would like to achieve higher levels of attendance, since doing so increases internal validity, it is not clear how much effort in time and resources should be devoted to increasing attendance. Extraordinary efforts are likely to decrease external validity. Given the priority of clinical trials on internal validity, it makes sense for clinically oriented researchers to design and implement experiments in such a way as to ensure a maximum 'dose' of treatment. To determine whether a clinically validated intervention would continue to produce positive outcomes in real world settings, however, it would seem that the focus needs to shift in the direction of external validity, and efforts to ensure high compliance may need to be relaxed, not because high attendance is not important and desirable, but because most community programs or systems of care do not have the resources to implement research-based interventions on an on-going basis with the same degree of attention to control, fidelity, and compliance as occurs in experimental studies. Taking into account the trade offs between internal validity and external validity in designing field studies calls for a delicate balance of competing objectives.

Acknowledgments This study was funded under a cooperative agreement from the National Institute on Drug Abuse, National Institutes of Health (NIDA/NIH), with support from the Center for Substance Abuse Treatment of the Substance Abuse and Mental Health Services Administration, the Centers for Disease Control and Prevention (CDC), the National Institute on Alcohol Abuse and Alcoholism (all part of the U.S. 
Department of Health and Human Services); and from the Bureau of Justice Assistance of the U.S. Department of Justice. The authors gratefully acknowledge the collaborative contributions of NIDA, the Coordinating Center (George Mason University/University of Maryland at College Park), and the Research Centers participating in CJ-DATS [Brown University, Lifespan Hospital; Connecticut Department of Mental Health and Addiction Services; National Development and Research Institutes (NDRI), Inc., Center for Therapeutic Community Research; the NDRI Center for the Integration of Research and Practice; Texas Christian University, Institute of Behavioral Research; University of Delaware, Center for Drug and Alcohol Studies; University of Kentucky, Center on Drug and Alcohol Research; University of California at Los Angeles, Integrated Substance Abuse Programs; and University of Miami, Center for Treatment Research on Adolescent Drug Abuse]. The contents are solely the responsibility of the authors and do not necessarily represent the views of the Department of Health and Human Services, the Department of Justice, NIDA, or other CJ-DATS participants. In addition, we thank the following people for their contributions to this paper: the TCM case managers, staff of ISAP's Data Management Centers, Elizabeth Hall, Tania Beaudoin, Elizabeth Nelson, CJ-DATS reviewers, and journal reviewers.

Open Access This article is distributed under the terms of the Creative Commons Attribution Noncommercial License which permits any noncommercial use, distribution, and reproduction in any medium, provided the original author(s) and source are credited.

\section{Addendum}

Technical note on trajectory group analysis

Consider a longitudinal set of variables $y_{i t}$ that take on the value 0 if person $i$ did not attend session $t$, and 1 if he/she attended. The model assumes that each person is a member of an unobserved trajectory group in the population. Each group has a unique pattern of session attendance over time. The model estimates both these trajectories and a person's probability of membership in them. The following more detailed description is largely taken from the discussion of Jones and Nagin (2007: 543-544).

First, the model assumes that the probability of attending any given session is represented by the equation

$$
P\left(Y_{i}\right)=\sum_{1}^{j} \pi_{j} P^{j}\left(Y_{i}\right)
$$

with $\pi_{j}$ representing the probability of membership in group $j$, and $P^{j}\left(Y_{i}\right)$ representing the probability of $y_{i t}$ (session attendance) across all time points $t$, conditional on membership in group $j$. Next, the model assumes that, for each person, the variables $y_{i t}$ are independent of each other, so $P^{j}\left(Y_{i}\right)$ can therefore be estimated as the product of the individual $p^{j t}\left(y_{i t}\right)$ from 1 to $t$. The group membership probabilities $\pi_{j}$ are estimated by multinomial logit. Finally, because the $y_{i t}$ are binary variables, $p^{j t}\left(y_{i t}\right)$ was equated to a binary logit model, $\mathrm{e}^{\beta j X} /\left(1+e^{\beta j X}\right)$, where $\mathrm{X}$ is the vector of variables representing time that were used in the model, and $\beta \mathrm{j}$ represents their estimated coefficients for group $j$. In our quadratic model there were two variables representing time, 'session number' and 'session number squared,' in addition to the intercept estimated in the binary logit model.

\section{References}

Angrist, J. D. (2006). Instrumental variables methods in experimental criminological research: what, why and how. Journal of Experimental Criminology, 2(1), 23-44. 
Baekeland, F., \& Lundwall, L. (1975). Dropping out of treatment: a critical review. Psychological Bulletin, $82(5), 738-783$.

Barnard, J., Frangakis, C. E., Hill, J. L., \& Rubin, D. B. (2003). Principal stratification approach to broken randomized experiments: a case study of school choice vouchers in New York City. Journal of the American Statistical Association, 98, 299-311.

Brecht, M. L., Greenwell, L., \& Anglin, M. D. (2005). Methamphetamine treatment: trends and predictors of retention and completion in a large state treatment system (1992-2002). Journal of Substance Abuse Treatment, 29, 295-306.

Brocato, J. O., \& Wagner, E. F. (2008). Predictors of retention in an alternative-to-prison substance abuse treatment program. Criminal Justice and Behavior, 35(1), 99-119.

Coviello, D. M., Zanis, D. A., Wesnoski, S. A., \& Alterman, A. I. (2006). The effectiveness of outreach case management in re-enrolling discharged methadone patients. Drug and Alcohol Dependence, 85, $56-65$.

Cox, G. B., Walker, R. D., Freng, S. A., Short, B. A., Meijer, L., \& Gilchrist, L. (1998). Outcome of a controlled trial of the effectiveness of intensive case management for chronic inebriates. Journal of Studies on Alcohol, 59(5), 523-532.

De Weert-Van Oene, G. H., Schippersb, G. M., De Jong, C. A. J., \& Schrijvers, G. J. P. (2001). Retention in substance dependence treatment: the relevance of in-treatment factors. Journal of Substance Abuse Treatment, 20, 253-261.

Gartin, P. R. (1995). Dealing with design failures in randomized field experiments: analytic issues regarding the evaluation of treatment effects. Journal of Research in Crime and Delinquency, 32(4), $425-445$.

Greene, W. H. (1993). Econometric analysis. Englewood Cliffs, NJ: Prentice Hall.

Hall, J., Vaughan-Sarrazin, M., Vaughn, T., Block, R., \& Schut, A. (1999). Iowa case management for rural drug abuse: preliminary results. Journal of Case Management, 1(4), 232-243.

Hall, E., Prendergast, M., Wellisch, J., Patten, M., \& Cao, Y. (2004). Treating drug-abusing women prisoners: an outcomes evaluation of the Forever Free Program. Prison Journal, 84(1), 81-105.

Hawkins, E. J., Baer, J. S., \& Kivlahan, D. R. (2008). Concurrent monitoring of psychological distress and satisfaction measures as predictors of addiction treatment retention. Journal of Substance Abuse Treatment, 35, 207-216.

Hiller, M. L., Knight, K., Broome, D. M., \& Simpson, D. D. (1998). Legal pressure and treatment retention in a national sample of long-term residential programs. Criminal Justice and Behavior, 25 (4), 463-481.

Hser, Y.-I., Joshi, V., Maglione, M., Chou, C.-P., \& Anglin, M. D. (2001). Effects of program and patient characteristics on retention of drug treatment patients. Evaluation and Program Planning, 24(4), 331-341.

Hubbard, R. L., Collins, J. J., Rachal, J. V., \& Cavanaugh, E. R. (1988). The criminal justice client in drug misuse treatment. In C. G. Leukefeld \& F. M. Tims (Eds.), Compulsory treatment of drug abuse: research and clinical practice (NIDA research monograph 86). Washington, DC: U. S. Government Printing Office, pp. 57-80.

Huber, D. L., Hall, J. A., \& Vaughn, T. (2001). The dose of case management interventions. Lippincott's Case Management, 6(3), 119-126.

Huber, D. L., Sarrazin, M. V., Vaughn, T., \& Hall, J. A. (2003). Evaluating the impact of case management dosage. Nursing Research, 52(5), 276-288.

SAS Institute (2006). The GLIMMIX Procedure, June 2006. Downloaded from http://support.sas.com/rnd/ app/papers/glimmix.pdf, May 5, 2008.

Jansson, L. M., Svikis, D. S., Breon, D., \& Cieslak, R. (2005). Intensity of case management services: does more equal better for drug-dependent women and their children? Social Work in Mental Health, 3(4), 63-78.

Jones, B. L., \& Nagin, D. S. (2007). Advances in group-based trajectory modeling and an SAS procedure for estimating them. Sociological Methods Research, 35(4), 542-571.

Justus, A. N., Burling, T. A., \& Weingardt, K. R. (2006). Client predictors of treatment retention and completion in a program for homeless veterans. Substance Use \& Misuse, 41, 751-762.

King, A. C., \& Canada, S. A. (2004). Client-related predictors of early treatment drop-out in a substance abuse clinic exclusively employing individual therapy. Journal of Substance Abuse Treatment, 26(3), 189-195.

Knight, K., Simpson, D. D., \& Hiller, M. L. (1999). Three-year reincarceration outcomes for in-prison therapeutic community treatment in Texas. Prison Journal, 79(3), 337-351.

Lang, M. A., \& Belenko, S. (2000). Predicting retention in a residential drug treatment alternative to prison program. Journal of Substance Abuse Treatment, 19, 145-160. 
Lefforge, N. L., Donohue B., \& Strada, M. J. (2007). Improving session attendance in mental health and substance abuse settings: a review of controlled studies. Behavior Therapy, 38(1), 1-22.

Lidz, V., Bux, D. A., Platt, J. J., \& Iguchi, M. Y. (1992). Transitional case management: a service model for AIDS outreach projects. In R. A. Ashery (Ed.), Progress and issues in case management (NIDA Research Monograph 127). Rockville, MD: National Institute on Drug Abuse, pp. 112-144.

Little, R. J., \& Yau, L. H. Y. (1998). Statistical techniques for analyzing data from prevention trials: treatment of no-shows using Rubin's causal model. Psychological Methods, 3(2), 147-159.

Longshore, D. L., Turner, S., \& Fain, T. (2005). Effects of case management of parolee misconduct: The Bay Area Services Network. Criminal Justice and Behavior, 32(2), 205-222.

Martin, S. S., Butzin, C. A., Saum, C. A., \& Inciardi, J. A. (1999). Three-year outcomes of therapeutic community treatment for drug-involved offenders in Delaware: from prison to work release to aftercare. Prison Journal, 79(3), 294-320.

Mateyoke-Scrivner, A., Webster, J. W., Staton, M., \& Leukefeld, C. (2004). Treatment retention predictors of drug court participants in a rural state. American Journal of Drug and Alcohol Abuse, 30(3), 605-625.

Mattson, M. E., Del Boca, F. K., Carroll, K. M., Cooney, N. L., DiClemente, C. C., et al. (1998). Compliance with treatment and follow-up protocols in project MATCH: predictors and relationship to outcome. Alcoholism: Clinical and Experimental Research, 22(6), 1328-1339.

McCaul, M. E., Svikis, D. S., \& Moore, R. D. (2001). Predictors of outpatient treatment retention: patient versus substance use characteristics. Drug and Alcohol Dependence, 62(1), 9-17.

McCoy, H. V., Dodds, S., Rivers, J. E., \& McCoy, C. B. (1992). Case management services for HIVseropositive IDUs. In R. A. Ashery (Ed.), Progress and issues in case management (NIDA Research Monograph 127). Rockville, MD: National Institute on Drug Abuse, pp. 181-207.

McGuire, J., Bilby, C. A. L., Hatcher, R. M., Hollin, C. R., Hounsome, J., \& Palmer, E. J. (2008). Evaluation of structured cognitive behavioural treatment programmes in reducing criminal recidivism. Journal of Experimental Criminology, 4(1), 21-40.

McLellan, A. T., Lewis, D. C., O’Brien, C. P., \& Kleber, H. D. (2000). Drug dependence, a chronic medical illness: implications for treatment, insurance, and outcomes evaluation. Journal of the American Medical Association, 284(13), 689-1695.

Moher, D., Schulz, K., \& Altman, D. (2001). The CONSORT Statement: revised recommendations for improving the quality of reports of parallel-group randomized trials. Journal of the American Medical Association, 285(15), 1987-1991.

Nagin, D. S. (1999). Analyzing developmental trajectories: a semi-parametric, group-based approach. Psychological Methods, 4, 139-157.

Nagin, D. S., \& Land, K. C. (1993). Age, criminal careers, and population heterogeneity: specification and estimation of a nonparametric, mixed Poisson model. Criminology, 31, 327-362.

National Institute on Drug Abuse. (2006). Principles of drug abuse treatment for criminal justice populations: a research-based guide. Bethesda, MD: National Institute on Drug Abuse, National Institutes of Health.

Prendergast, M., \& Cartier, J. (2008). Improving parolees' participation in drug treatment and other services through strengths case management. Perspectives, 32(1), 38-46.

Prendergast, M., Farabee, D., \& Cartier, J. (2005). Eighth annual report on the evaluation of the California Substance Abuse Treatment Facility (SATF-SAP) and State Prison at Corcoran. Submitted to the Office of Substance Abuse Programs, California Department of Corrections and Rehabilitation. Los Angeles: University of California, Los Angeles, Integrated Substance Abuse Programs.

Pulford, J., \& Wheeler, A. (2007). Documenting clinic attendance norms: raw data and implications for treatment practice. Journal of Substance Abuse, 12(2), 95-102.

Sacks, S., McKendrick, K., Sacks, J. Y., Banks, S., \& Harle, M. (2008). Enhanced outpatient treatment for co-occurring disorders: main outcomes. Journal of Substance Abuse Treatment, 34(1), 48-60.

Siegal, H., \& Rapp, R. (eds). (1996). Case management and substance abuse treatment: practice and experience. New York: Springer

Siegal, H., Rapp, R., Fisher, J., Cole, P., \& Wagner, J. (1993). Treatment dropouts and noncompliers: two persistent problems and a programmatic remedy. In J. Inciardi, F. Tims \& B. Fletcher (Eds.), Innovative approaches in the treatment of drug abuse: program models and strategies. Westport, $\mathrm{CT}$ : Greenwood Press, pp. 87-96.

Simpson, D. D., \& Joe, G. W. (1993). Motivation as a predictor of early dropout from drug abuse treatment. Psychotherapy, 30, 357-368.

Simpson, D. D., Joe, G. W., \& Brown, B. S. (1997a). Treatment retention and follow-up outcomes in the Drug Abuse Treatment Outcome Study (DATOS). Psychology of Addictive Behaviors, 11(4), 294307. 
Simpson, D. D., Knight, K., \& Broome, K. M. (1997b). TCU/CJ forms manual: drug dependence screen and initial assessment. Fort Worth, TX: Texas Christian University, Institute of Behavioral Research. Forms available from Internet website at www.ibr.tcu.edu.

Singer, J. D. (1998). Using SAS PROC MIXED to fit multilevel models, hierarchical models, and individual growth models. Journal of Educational and Behavioral Statistics, 23(4), 323-355.

Siqueland, L., Crits-Christoph, P., Gallop, R., Barber, J. P., Griffin, M. L., et al. (2002). Retention in psychosocial treatment of cocaine dependence: predictors and impact on outcome. American Journal on Addictions, 11(1), 24-40.

Sterling, R. C., Gottheil, E., Weinstein, S. P., \& Serota, R. (2002). Therapist/patient race and sex matching: treatment retention and 9-month follow-up outcome. Addiction, 93(7), 1043-1050.

Stotts, A. L., Mooney, M. E., Sayre, S. L., Novy, M., Schmitz, J. M., \& Grabowski, J. (2007). Illusory predictors: generalizability of findings in cocaine treatment retention research. Addictive Behaviors, 32, 2819-2836.

Sung, H.-E., Belenko, S., Feng, L., \& Tabachnick, C. (2004). Predicting treatment noncompliance among criminal justice-mandated clients: a theoretical and empirical exploration. Journal of Substance Abuse Treatment, 26(1), 13-26.

Ventura, L. A., Cassel, C. A., Jacoby, J. E., \& Huang, B. (1998). Case management and recidivism of mentally ill persons released from jail. Psychiatric Services, 49(10), 1330-1337.

Wexler, H. K., Melnick, G., Lowe, L., \& Peters, J. (1999). Three-year reincarceration outcomes for Amity in-prison therapeutic community and aftercare in California. Prison Journal, 79(3), 312-336.

Michael Prendergast Ph.D., is Director of the Criminal Justice Research Group at the UCLA Integrated Substance Abuse Programs (ISAP). He has been Principal Investigator of evaluations of various treatment programs in correctional settings in California, including a five-year follow-up study of participants in a prison-based therapeutic community, an evaluation of the use of vouchers within a drug court treatment program, and an evaluation of the relative effectiveness of mixed-gender and women-only community treatment. He is Principal Investigator of the Pacific Coast Research Center of the NIDA-funded Criminal Justice Drug Abuse Treatment Studies (CJ-DATS).

Lisa Greenwell Ph.D. is a Senior Statistician at the UCLA Integrated Substance Abuse Programs. Her statistical expertise includes advanced regression analysis (e.g., mixed models), meta-analysis, generalized estimating equations, longitudinal analyses (e.g., survival analysis, growth modeling), and sample selection models (e.g., inverse Mills ratio, propensity scores). Her research interests include the influence of sociodemographic disparities and social networks on drug users' well-being and the public health implications of incarceration. She earned a Ph.D. in Sociology from Indiana University and was a Postdoctoral Fellow in Population Studies at RAND.

Jerry Cartier M.A. has considerable experience in the drug and alcohol treatment field as a practitioner, administrator, and researcher. After joining UCLA-ISAP in 1998, he became Study Director for an evaluation of the California Substance Abuse Treatment Facility/State Prison (SATF) treatment programs. He was Study Director for the Transitional Case Management Study (TCM), one of the NIDA-funded studies in the Criminal Justice Drug Abuse Treatment Studies initiative. Mr. Cartier currently serves as Study Coordinator for two NIDA-funded studies on correctional drug treatment.

Joann Y. Sacks Ph.D., is the Executive Director of National Development and Research Institutes, Inc. (NDRI) in New York City. Dr. Sacks has been involved in the design, implementation and evaluation of treatment models for special populations (individuals with co-occurring disorders (COD) and women) for the past 20 years. She is an expert in training, technical assistance and implementation of evidence-based practices for specialized populations. Dr. Sacks' NIDA- and SAMHSA-funded research has focused on the use of research data to improve treatment practices for single adults and homeless families within community agencies as well as state correctional treatment systems, and the use of treatment outcome and cost information to inform policy and planning on a national and state level.

Linda Frisman Ph.D., is Research Professor for the University of Connecticut School of Social Work, and serves as the Director of Research at the Connecticut Department of Mental Health and Addiction Services. Dr. Frisman holds a Ph.D. in Social Policy from the Heller School of Brandeis University, where 
she was a National Institute of Mental Health trainee in the economics of mental health care. She was also an NIMH post-doctoral fellow in mental health services research at Yale University. Dr. Frisman specializes in cost-effectiveness studies. She has been the Principal Investigator of several federally funded studies testing interventions that address homelessness, co-occurring mental health and substance use disorders, and criminal justice populations with behavioral health disorders. Currently, she is the Principal Investigator of the Connecticut Criminal Justice Drug Abuse Treatment Studies (CJDATS) Center funded by the National Institute on Drug Abuse.

Eleni Rodis MS, is a project director for the Research Division of the Connecticut Department of Mental Health and Addiction Services, and is on the staff of the University of Connecticut School of Social Work. With a background in clinical psychology, she has worked on several federally funded studies testing interventions that address homelessness, co-occurring mental health and substance use disorders, and criminal justice populations with behavioral health disorders, as well as several evaluations of state-run programs for people with serious mental health and/or substance use disorders.

Jennifer R. Havens has a PhD in epidemiology as well as a Masters in Public Health (MPH) from the Johns Hopkins School of Public Health. Her research interests include the epidemiology of prescription drug abuse, rural health disparities specific to substance use, and the infectious complications of injection drug use, namely HIV and hepatitis C. Dr. Havens is currently funded through the National Institutes of Health to examine social networks and HIV risk among rural drug users. 